\title{
Developed democracies versus emerging autocracies: arts, democracy, and innovation in Quadruple Helix innovation systems
}

\author{
Elias G Carayannis ${ }^{* *}$ and David FJ Campbell ${ }^{2,3}$
}

\footnotetext{
* Correspondence: caraye@gwu.edu ${ }^{1}$ European Union Research Center, Department of Information Systems \& Technology Management, School of Business, The George Washington University, Duquès Hall, Funger Hall, Suite 515C, 2201 G Street, NW, Washington, D.C 20052, USA

Full list of author information is available at the end of the article
}

\begin{abstract}
Arts, democracy, and innovation co-evolve. While for the Triple Helix model the existence of a democracy is not necessary for knowledge production and innovation, the Quadruple Helix is here more explicit. The way how the Quadruple Helix is being engineered, designed, and 'architected' clearly shows that there cannot be a Quadruple Helix innovation system without democracy or a democratic context. The following attributes and components define the fourth helix in the Quadruple Helix: 'media-based and culture-based public,' 'civil society,' and 'arts, artistic research, and arts-based innovation'. By this, the fourth helix in the Quadruple Helix represents the perspective of the 'dimension of democracy' or the 'context of democracy' for knowledge, knowledge production, and innovation. This is particularly true when democracy is to be understood to transcend the narrow understanding of being primarily based on or being primarily rooted in government institutions (within Triple Helix). Civil society, culture-based public, quality of democracy, and sustainable development convincingly demonstrate what the rationales and requirements are for conceptualizing democracy broader. Political pluralism in a democracy co-evolves with the pluralism, diversity, and heterogeneity of knowledge, knowledge production, and innovation ('Democracy of Knowledge'). The Quintuple Helix extends the Quadruple Helix by aspects of the 'natural environments of society and economy,' 'social ecology,' and the 'socioecological transition'. Also, this environmental context of society can be better addressed in a democracy than in a non-democracy. The current world appears to be challenged by a race between developing democracies versus emerging autocracies over knowledge production and innovation. The contributions of arts, arts-based research, and arts-based innovation to knowledge production and innovation systems are manifold. Art helps and aids us in thinking 'beyond the box'. The traditional understanding of arts emphasizes the aesthetic dimension of arts. Art and arts can also be understood (and re-invented) as a manifestation of knowledge, knowledge production, and knowledge creation. Arts and artistic research are now being regarded as drivers for forming and pluralizing interdisciplinary and transdisciplinary configurations and networks with research in the sciences and the application and use of knowledge and innovation in the context of not only society and democracy, but also the economy. Art, arts-based research, and arts-based innovation contribute to creating (co-creating) the basis for new models of economic growth. This indicates opportunities for a creative design or creative design processes in the further co-evolution of knowledge economy, knowledge society, and knowledge democracy.

(Continued on next page)
\end{abstract}

\section{Springer}

(c) 2014 Carayannis and Campbell; licensee Springer. This is an Open Access article distributed under the terms of the Creative Commons Attribution License (http://creativecommons.org/licenses/by/4.0), which permits unrestricted use, distribution, and reproduction in any medium, provided the original work is properly credited. 
(Continued from previous page)

Keywords: AAA (arts, artistic research, and arts-based innovation); Co-evolution; Cross-employment and multi-employment; Democracy of knowledge; Socioecological transition; Multi-level innovation systems; Innovation ecosystem; Twentyfirst century Fractal Research and Education and Innovation Ecosystem (FREIE); Networks and network governance; Linear and non-linear innovation; Quadruple Helix innovation systems; Quadruple Helix Plus; Quintuple Helix

\section{Background}

The following is the vision and manifesto for knowledge production and innovation in Quadruple Helix innovation systems: arts, democracy, and innovation co-evolve. This is being stated explicitly by the concept and model of the Quadruple Helix innovation systems (Carayannis and Campbell 2006, 2009, 2010) ${ }^{\mathrm{a}}$. How does the Quadruple Helix ${ }^{\mathrm{b}}$ differ from 'N-Tuple of Helices' (Leydesdorff 2012)? N-Tuple of Helices on the one hand, and the Quadruple Helix and the Quintuple Helix innovation systems (Quadruple Helix Plus) on the other, are not driven by the same emphasis, and their ramifications point into different directions (for a summary and overview, see also the interview in Park 2014). While the N-Tuple of Helices can be regarded as an abstract meta-concept of helices, the Quadruple Helix is more concrete in its qualities by being interested in developing and proposing solutions and problem-solving approaches based on a broader conceptual and theoretical understanding. The Quadruple Helix focuses (as a final test) on reform, strategy, policy, and implementation processes and on transformation of economy, society, and democracy (economy in democracy). The Quintuple Helix could be interpreted as a Quadruple Helix Plus extension, thus representing a further development and evolution in the line of thinking that integrates the ecology (also social ecology) into our approaches for knowledge production and innovation (Carayannis and Campbell 2010; Carayannis et al. 2012).

The market should serve society, and the society should serve the people and individuals (and not the other way around). The role of the individual is paramount. Quadruple Helix emphasizes that 'people matter'. First of all, the Quadruple Helix is 'human-centered' and only secondarily 'institution-oriented'. The Quadruple Helix operates with a strong bottom-up momentum and encouragement. Therefore, for the Quadruple Helix, democracy matters and is key and crucial. Quadruple Helix addresses knowledge production and innovation in the context of democracy. There cannot be a Quadruple Helix (or Quintuple Helix) 'outside' (or without) democracy. Here we see a co-development and co-evolution of democracy and knowledge production and innovation for knowledge society and knowledge democracy. This addressed and asserted co-evolution of the Quadruple Helix (Quintuple Helix) with democracy is even more plausible, when democracy is not being understood in terms of a 'narrow' electoral democracy, but when democracy is being carried and driven by a 'broader' conceptual understanding, for which freedom, equality, sustainable development, and the idea of 'quality of democracy' are equally crucial (Campbell and Carayannis 2013a; 2015).

Triple Helix is possible within a democracy. However, Triple Helix is also possible without a democracy. The Triple Helix focuses on the knowledge economy, which may be 
approached by a non-democratic framework. Non-democratic (authoritarian) political regimes may be tempted to implement varieties of Triple Helix designs. Per definition, to already begin with a conceptual starting point, it is impossible for a non-democratic (authoritarian) political regime to try to implement a Quadruple Helix. There is no Quadruple Helix without democracy. In addition, evidence suggests that the ecological sensitivity of the Quintuple Helix (Carayannis et al. 2012) can be more easily or realistically be implemented and promoted within a democratic context of knowledge production and innovation. For the Quadruple Helix, the 'democracy matters': this is in line with a view of a 'Neo-Renaissance' where democracy encourages development in action for smart, sustainable, and inclusive growth, by this advocating sustainable development. This should allow for 'happy accidents'. For discourses on knowledge and innovation, a Democracy versus Technocracy issue can be postulated, where technocratic (and bureaucratic) approaches to innovation in non-democratic regimes are being questioned and challenged by knowledge production and innovation in democracies. Also, for the developing countries and emerging markets, this has implications and ramifications, where there should be expectations that developments in knowledge and innovation are paralleled by progress in democratization (of course, this may not be always the case in empirical terms or empirically). Democracy acts as one of the levers that happy accidents in knowledge production and innovation are being transformed and translated into opportunities and benefits for society and to the people. Can there also be a 'democratic capitalism', and which attempts of realization can there be approached or tried out (Carayannis and Kaloudis 2010)?

The fourth helix in the Quadruple Helix consists of the following components or attributes: the 'media-based and culture-based public', 'civil society', and 'arts, artistic research, and arts-based innovation'. This fourth helix also could be paraphrased as the dimension of democracy (knowledge democracy) or the dimension of knowledge society in the context of democracy. Arts-based research offers opportunities for interdisciplinary and transdisciplinary configurations, re-configurations, and networks with the knowledge production in the sciences-based research. Arts-based innovation liberates the concept of innovation from primarily economically driven concerns and purposes, and encourages creativity for processes of knowledge production and innovation. Artsbased research and arts-based innovation possibly lead to a re-thinking and remodeling (and 're-invention') of economic growth models not only in the advanced economies, but also in the emerging markets.

Metrics for a possible measurement of Quadruple Helix (Quintuple Helix) innovation systems could emphasize the following aspects and considerations: (1) the degree of pluralism, diversity, and heterogeneity of different forms and paradigms of knowledge, knowledge production, and innovation; and (2) the degree of networks and their dynamics and connectivity across the pluralistic architecture of knowledge and innovation. This would imply to look at the pluralism of knowledge and innovation and the pluralism of their structures and processes by which knowledge and innovation are interconnected and interwoven in networks and in 'networks in clouds and crowded crowding clouds'. Networking and 'clouds' ('crowds') implies to focus in greater detail on the connecting synapses in the architecture of knowledge and innovation systems. This notion of pluralism in knowledge and innovation is also being captured by the idea of 'Democracy of Knowledge', meaning that the 
pluralism in knowledge production communicates with pluralism (political pluralism) in a democracy, proposing here a co-evolution of democracy with systems of knowledge production and innovation (Carayannis and Campbell 2009, 2012, p. 55). Metrics of measurement of knowledge and innovation should therefore be sensitive for expressing, displaying, and mapping pluralism, diversity, and heterogeneity. Furthermore, the argument could be set up for discussion that forms or types of knowledge production may correspond with forms and types of innovation systems. Congruencies here could be as follows: Triple Helix innovation (Etzkowitz and Leydesdorff 2000) interacts with 'Mode 1' and 'Mode 2' knowledge production (Gibbons et al. 1994), while Quadruple Helix and Quintuple Helix innovation systems refer to a 'Mode 3' type of knowledge production. In terms of pluralism and diversity, the Quadruple Helix (Quintuple Helix) appears to be better designed and adapted for the social environments of democracy and advanced economies. In economic model building, the concept of 'isoquants' (Isoquanten) expresses relationships between indicators or factors and furthermore demonstrates what happens with regard to these patterns of interaction when there is a tendency or momentum of higher development. Higher levels of development could be accompanied by shifts in patterns of correspondence. In Figure 1, we suggest how an econometric model of isoquants could be applied to types of knowledge production and innovation systems. Figure 1 indicates opportunities for developing mature metrics of measurement for knowledge production and innovation systems. For further debate, there also should be a focus and sensitivity for how artsbased research and arts-based innovation influence and contribute to economic growth and thus may alter our models that underlie approaches to economic progress. There is an expectation that creativity is being crucially cross-fertilized by pluralism and heterogeneity in knowledge production and innovation. Without creativity, innovation is not viable in the long run.

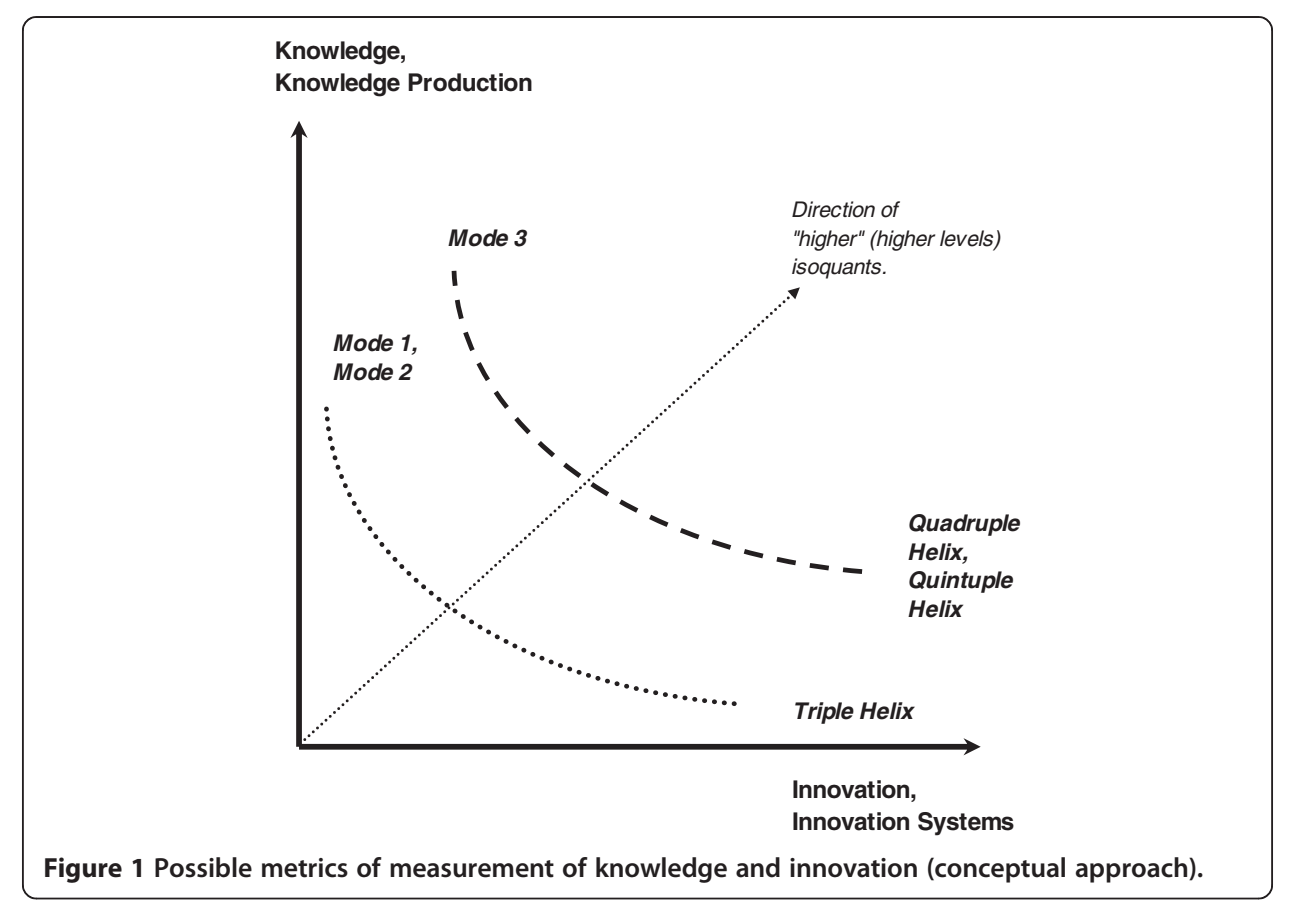




\section{Results and discussion}

\section{Research questions on artistic research}

This article contribution does not focus on the arts as such. The focus is on 'artistic research' and how artistic research relates to research, knowledge production (knowledge creation), innovation, and innovation systems. Artistic research may also have the potential to help us to better understand the arts themselves. By this, artistic research qualifies as an epistemic approach ('epistemic tool') that navigates to core meanings of arts and of 'art in the arts'. Artistic research, however, also bridges, cross-connects, and links the arts with knowledge production (research) and knowledge application (innovation) in the sciences or research and innovation that are based on the sciences ${ }^{c}$. Therefore, at least potentially, artistic research is also interdisciplinary in character. Artistic research adds to the development and formation of designs and architectures of interdisciplinary research platforms and research as well as innovation networks, where different disciplines in the sciences are interconnected with the disciplines in the arts through research and innovation activities. In fact, interdisciplinary ambitions in the sciences are reinforced and excelled by bringing artistic research into play. Artistic research and also the arts in general help in creatively strengthening and unfolding the interdisciplinary drive in the sciences. In one understanding, interdisciplinarity does not happen 'automatically' in the organizational context of the sciences but requires an involvement of structures and processes that encourage a further development of interdisciplinarity (within the institutional framework of universities or of other higher education institutions). For example, academic careers often follow a disciplinary logic; therefore, inserting and introducing interdisciplinarity to organizations and networks requires to innovate and to re-invent the academic career logic. The organizational framing of transdisciplinarity creates even further challenges (on interdisciplinarity and transdisciplinarity; see for example Arnold 2013a, 2013b). There exists and is the opportunity of configuring and re-configuring scientific research (research in the sciences) and artistic research, interwoven in arrangements of interdisciplinarity and transdisciplinarity. In fact, artistic research has all the potential to increase interdisciplinarity and transdisciplinarity also in research in the sciences, when scientific research and artistic research are being interlinked.

Our analysis is being driven by the following core research question: How does artistic research relate to research in the sciences, and how does artistic research relate to innovation and innovation systems? Our inclination is to engage further in formulating, developing, and designing propositions in reference to our research question. These propositions are more tentative in character; additional 'research about research' is necessary and may impact future research agendas. The analysis of our research question will be based on Carayannis and Campbell (2013) and will depart in iterations conceptually from there. We are motivated to inquire connections of artistic research to innovation and innovation systems by relying on and by applying consequently the concepts of the Quadruple and Quintuple Helix innovation systems. In fact, we believe that the Quadruple and Quintuple Helixes are designed (and driven) in a way and are carried by an understanding that emphasizes the importance of arts, arts universities, and artistic research for creativity, knowledge production, and innovation. Triple Helix represents a basic model of the innovation core and was developed by Etzkowitz and 
Leydesdorff (2000; Leydesdorff 2012). Quadruple Helix (Carayannis and Campbell 2009) and Quintuple Helix (Carayannis and Campbell 2010) bring in additional perspectives and by this already 'contextualize the context' (see Figure 2). When we develop the importance and meaning of artistic research for research and innovation, we will follow in particular the conceptual logic of the models of the Quadruple and Quintuple Helix innovation systems. These models will serve as reference for artistic research. The Quadruple Helix and the Quintuple Helix express and emphasize why arts and artistic research are important for knowledge production and innovation.

Our following analysis is structured in the following sections. In the 'Arts and artistic research' section, we explore further the cross-connections and interconnection between arts and artistic research. This is based on an understanding of arts as a manifestation of knowledge. The 'Innovation systems in conceptual evolution: Mode 3 knowledge production in Quadruple and Quintuple Helix innovation systems' section embeds artistic research in the context of the concepts of Quadruple and Quintuple Helix innovation systems. We demonstrate how concepts of innovation and innovation systems have evolved and how knowledge production, innovation, and

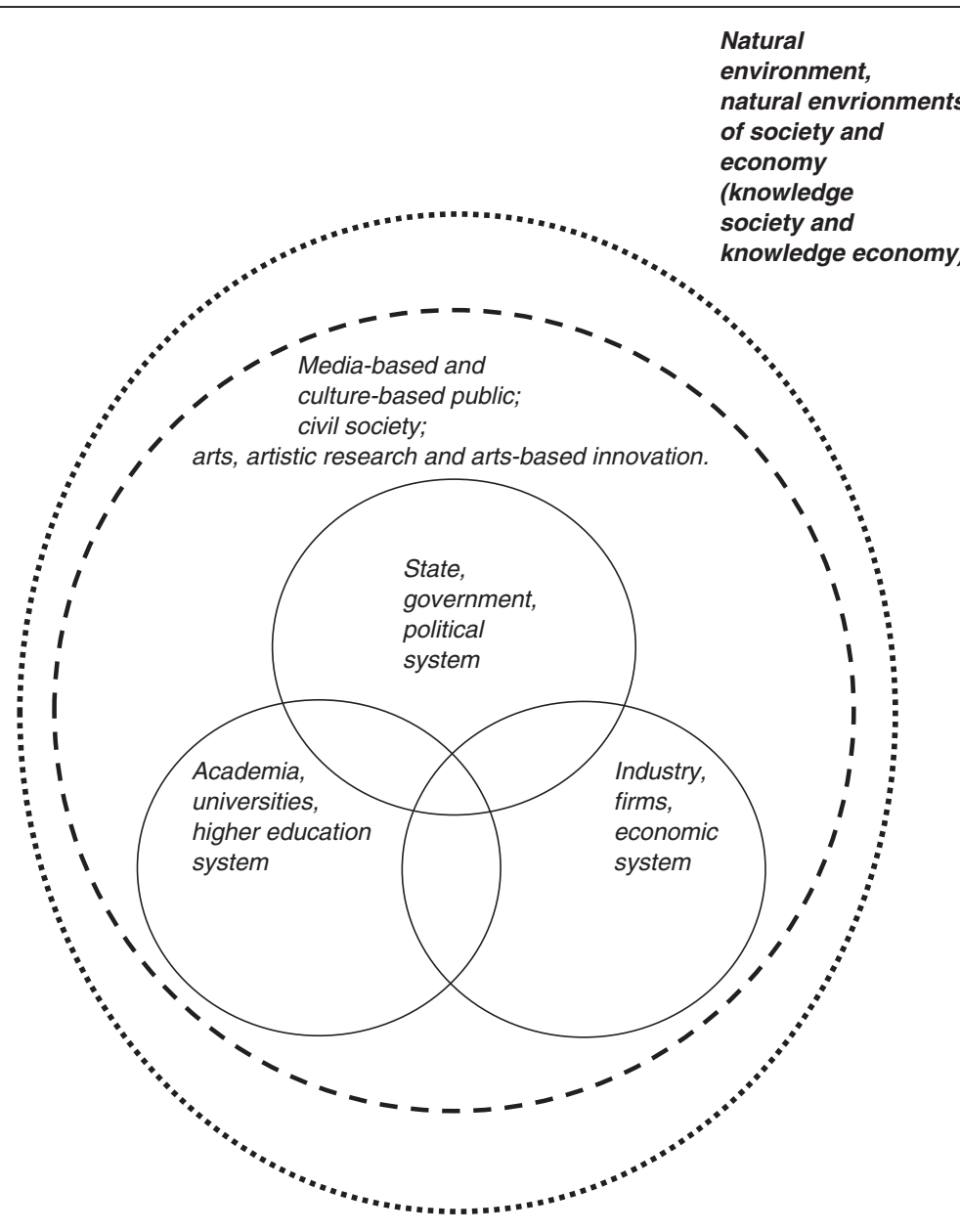

Source: Authors' own conceptualization based on Carayannis and Campbell (2010, p. 62; 2013). 
structures of organizations are intertwined in co-evolution. Finally, in the 'Conclusions' section, the conclusion to our analysis, we speculate on possible future scenarios of codevelopment of arts, research, innovation, and society. This co-development has all the potentials of becoming crucial for the further progress of innovation and innovation systems that drives knowledge economy, knowledge society, and knowledge democracy.

\section{Arts and artistic research}

What is art or what are the arts? This creates a challenge in the quest for finding or identifying answers. However, for our analysis presented here, a possible definition of arts is not of primary concern, because we will focus with greater emphasis on artistic research and its ramifications for knowledge production and innovation. Therefore, we reflect more briefly on the issue of what art is or what arts may be considered to be. There exists not only one definition, but a pluralism of different definitions of arts (e.g., see Campbell 2013b). We must recognize and should acknowledge a variety of different definitions of arts, also with competing, sometimes even conflicting meanings. There are contradictions between the available definitions of arts. Also, definitions of arts have changed over time and continuously will do so and are furthermore context-dependent. Are the arts older than the sciences? Art (as a concept and practice) exists now for several hundred, better several thousand, years (at least), so there was a sufficiently long time for a serious evolution of arts. Art (as a concept and practice) probably is even older than the sciences (modern sciences). ${ }^{\mathrm{d}}$ A pragmatic simplification could suggest that art is what artists are doing (and artists do very different things). Consequently, 'established art' is being represented by the established artists. But there exists no universal criterion or general standard as to who may qualify (or not) being an artist. We know that several of the most influential (and innovative) artists only had an impact later in their life, if not even for later generations. In these cases, the not-established (non-established) artists were even more important.

A 'traditional' understanding of arts frequently associates the arts with an 'aesthetic' dimension, which could be more abstract or more concrete. More concrete means to indicate a 'perceived beauty' also as an emotionally perceived beauty. Emotions imply then that beauty causes or is connected to emotions in the human 'observer' (also producer) of arts, when art is being perceived (created). The emotional spectrum can be comprehensive and diversified, and also controversial. Looking at art from a historical perspective, the aesthetic dimension of arts often was thought to express the beauty or perfect beauty (perfect order) of the world (the universe), of society, and also of individual people (for example, see the review and discussion in Öcal 2013, pp. 11 to 27). ${ }^{e}$ This expression of beauty or perfection (beautiful perfection) could have religious connotations but was not necessarily linked to religious connotations. In several contexts, also cross-references were drawn between the beautiful, the perfect, and the good. Was this the case (the construction of meaning), then the beautiful was furthermore the morally or ethically good. The 'beautiful order' expressed the 'morally good order'. By associating art closely to an aesthetic dimension, arts can also fulfill 'aesthetic functions' or also those aesthetic functions, which society or specific communities want to assign to arts. Acknowledging modern (post-modern) reactions against traditional (too traditional) aesthetical concepts and conceptions of beauty, the aesthetic dimension may also be sub-clustered into a complex world of very different sub-dimensions. Can the absence 
of beauty also be expressed in the aesthetical dimension? Is there the 'beauty of the non-beauty' or the 'beauty of the ugly', and does the ugly also fulfill aesthetic functions? Does the aesthetic dimension capture equally the presence and also the absence of beauty? Can beauty (aesthetics) be measured without referring to a specific context? In a terminology of measurement of beauty, beauty could be represented on a dimension (a scale or multi-dimensional scale) of aesthetics that expresses the presence (presence and/or absence) of beauty, allowing for gradual degrees of beauty or also the expression of 'positive beauty' and 'negative beauty'.

In addition to aesthetics, what are the possible alternative dimensions for conceptualizing and 'measuring' the arts that complement and expand the aesthetic dimension of arts? Beyond aesthetics, how can we conceptualize arts further? In fact, we are interested in also promoting an understanding of arts which drives arts further and beyond an only-aesthetic-understanding of arts, which does not deny the aesthetic dimension (dimensions) but intends to complement the aesthetic dimension of arts. Therefore, we want to suggest the following as a new reference point for debate:

Art and arts can also be understood (and re-invented) as a manifestation of knowledge, knowledge production and knowledge creation. Furthermore, knowledge production and knowledge creation extend to knowledge application and knowledge use.

The here presented approach to arts introduces knowledge as an additional dimension for defining and understanding arts. This additional dimension does not replace but extends the aesthetic dimension of arts, by this making the arts clearly multi-dimensional (see Figure 3). ${ }^{\mathrm{f}}$ Consequences of this are (when we follow the logic of that particular knowledge definition of arts) that the arts cannot be understood comprehensively and sufficiently only on the basis of aesthetics alone. Of course, we could speculate whether the knowledge involvement of arts implies a knowledge for which aesthetic considerations play frequently an important role (forms of beauty or non-beauty). ${ }^{\mathrm{g}}$ Aesthetics may interact with different forms of reasoning or intelligence, such as intuition or emotional intelligence. Research and progress in the sciences clearly are also driven by and benefit obviously from intuition or emotional intelligence. Clearly, there is furthermore more of a need to continuously reflect which dimensions (in addition to aesthetics and knowledge) may also be of further relevance for art and arts.

By introducing this additional knowledge dimension of arts, complementing the dimension of aesthetics, it is being acknowledged that also forms of arts-based research and arts-based innovation are existing and can emerge further. In fact, artistic research represents one crucial expression of arts as a manifestation of knowledge. What are the differences between arts-based research and artistic research? Boundaries here are obviously fluid and depend on specific positions of perspective. Connotations of artistic research imply that the research is not only arts-based, but that research and arts are actually being intertwined and interlinked with each other more directly (on 'artistic research', see furthermore Damianisch 2013 and Mateus-Berr 2013). Artistic research is more immediately and straightforwardly connected to the arts than arts-based research, at least being seen from a conceptual understanding. Of course, also artistic research and arts-based research overlap. In fact, opportunities of interdisciplinary and transdisciplinary combinations of artistic research, arts-based research, and academic research (in the 


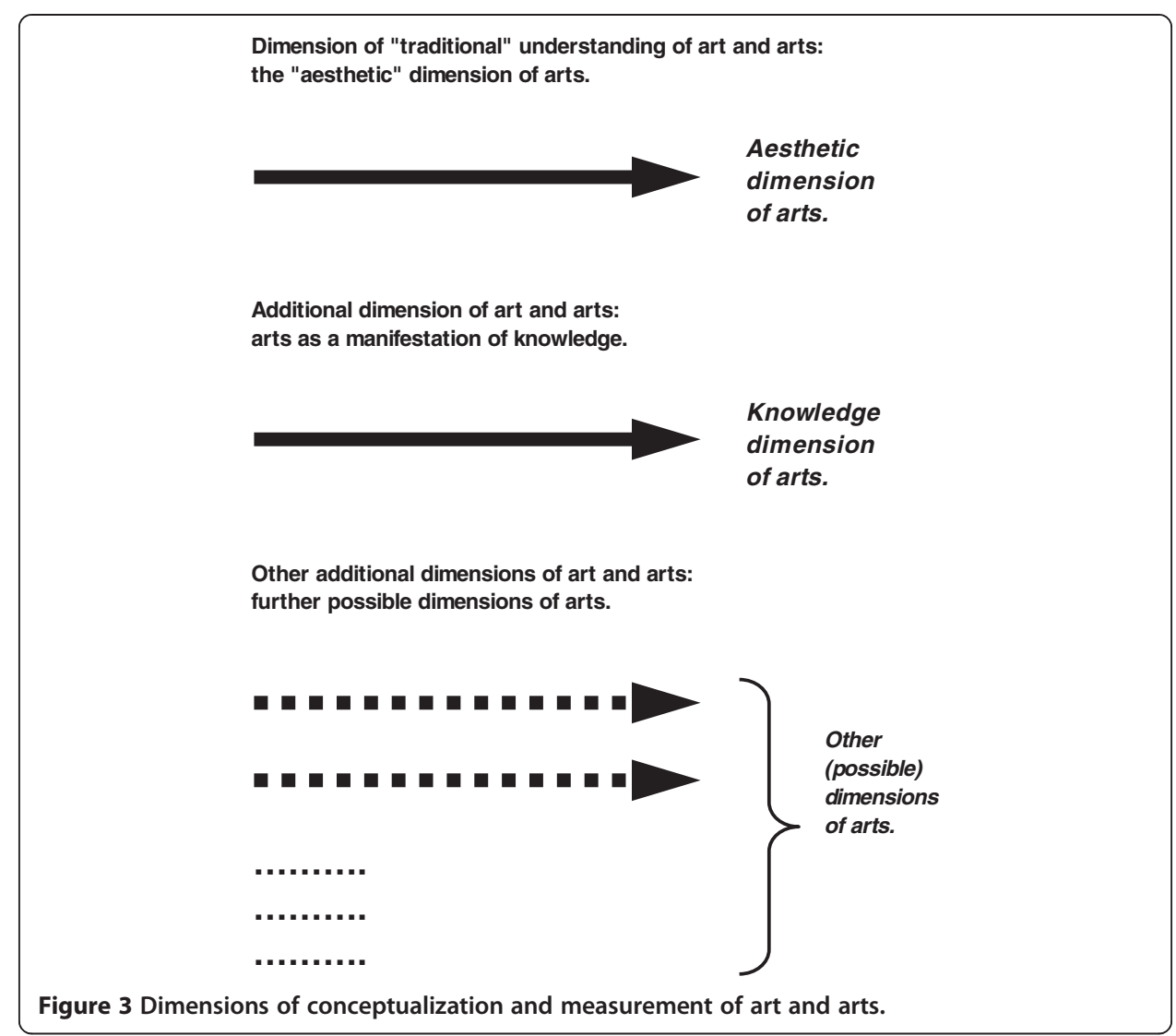

sciences), extended by configurations of arts-based innovation and sciences-based innovation, are arising and can be utilized by institutions, organizations, communities, and networks. 'In a short-cut, transdisciplinarity may be defined as the application of interdisciplinarity (transdisciplinarity = application of interdisciplinarity?)' (Campbell and Carayannis 2013a, p. 34). Of course, we have to admit that there also can be the transdisciplinarity of a 'disciplinarity in application'. Transdisciplinarity usually (always) refers to forms of application. Often (but not always), interdisciplinarity is more application-friendly than disciplinarity (see again Arnold 2013b).

The proposition (that knowledge, knowledge production, and knowledge creation qualify as an additional dimension for art and arts) has the implication that the arts and our understanding of arts are being opened to knowledge and the 'tree of ramifications' of knowledge. In fact, this bridges the arts with research and innovation. The arts are interconnected with research and innovation in the arts and with research and innovation in the sciences. 'Art as a manifestation of knowledge' draws interdisciplinary and transdisciplinary configurations in connectivity, where knowledge production and innovation in the arts are extended to knowledge production and innovation beyond the arts. Furthermore, we can argue that in the context of a knowledge understanding of the arts, the artistic research actually is important for comprehending arts and also for developing the arts further. (There is no comprehensive understanding of the arts without artistic research?) Artistic research also touches on epistemic implications for the arts. Already in the introduction, we asserted 'By this, artistic research qualifies as an epistemic approach ("epistemic tool") that navigates to core meanings of arts and of 
"art in the arts"'. Is aesthetics more than only-beauty, or what is the beauty of epistemology?

Having introduced knowledge, knowledge production, and knowledge creation as a second dimension for art and arts, in addition to the dimension of aesthetics, we want to speculate on some of the implications and ramifications of this intellectual endeavor. The following are the propositions we want to suggest for further discussion:

1. Art as a manifestation of knowledge: Our proposition is that art and arts can also be understood as a manifestation of knowledge. This knowledge-based definition refers to knowledge production and knowledge creation (research) ${ }^{\mathrm{h}}$ as well as to the application and use of knowledge (innovation). We introduced knowledge as a second (additional) dimension for defining arts that complements the first (and more traditional) dimension of arts, which is aesthetics. In our opinion, knowledge does not replace but complements aesthetics for a broader understanding of arts. Dimensions in addition to aesthetics and knowledge appear also to be possible and valid for arts. (In the context of our analysis here, however, we do not engage further in speculating on dimensions of arts beyond aesthetics and knowledge.)

2. Arts, artistic research, interdisciplinary, and transdisciplinary combinations of research in the arts and research in the sciences, innovation, and innovation systems: Artistic research represents one outflow in the consequence of approaching arts as a manifestation of knowledge. In fact, it could be argued that artistic research helps in better understanding arts in all the possible ramifications. To turn the argument, without artistic research, our pictures of arts are incomplete, probably also too fragmented. Without artistic research, our visions of arts are insufficient. Based on this paradigm of knowledge, arts as a manifestation of knowledge and artistic research clearly enable to cross-connect and interconnect the arts with knowledge. Discourses in knowledge are being bridged with discourses in the arts. Research and innovation can spread from the domain of knowledge to the domain of arts. Arts and artistic research are now being regarded as drivers for forming and pluralizing interdisciplinary and transdisciplinary configurations and networks with research in the sciences and the application and use of knowledge and innovation in the context of not only society and democracy, but also the economy. Arts and artistic research aid and add in widening our horizons of knowledge production and knowledge creation within the sciences. With arts and artistic research, the domain (domains) of intelligence can be more fully leveraged for knowledge creation, which is also important for knowledge production in the sciences. What are forms or sources of knowledge production (intelligence) beyond language or the use of (written) texts? Arts may also be utilized as an unconventional strategy for preparing grounds for The New 'beyond horizon', for encouraging and experimenting with unconventional configurations of 'interdisciplinarity in transdisciplinarity'. Arts as a manifestation of knowledge and artistic research redefine the arts in a way, making it then obvious as to why the arts are crucial (at least potentially) for innovation and whole innovation systems (national systems of innovation or multi-level innovation systems; Carayannis and Campbell 2006; Carayannis and Campbell 2012, pp. 32 to 35). One radical proposition would be that without strong and continuously evolving cross-references to arts, every comprehensive innovation system (national or multi-level architectured innovation system) is only 
premature, operating below possible capabilities. 'The arts excel as innovation systems'. Arts and artistic research also contribute to Quality of Democracy and innovation capabilities in democracies and in processes of further democratization (Campbell and Carayannis 2013a).

3. Epistemic implications of arts and artistic research: Arts as a manifestation of knowledge and artistic research also emphasize the epistemic implications of arts. ${ }^{\mathrm{i}}$ This is not being seen as being in conflict with the aesthetic dimension of arts, since beauty or non-beauty are per se neutral with regard to epistemic potentials. Epistemic ramifications of arts and artistic research are manifold, diverse, and heterogeneous. For example, artistic research engages the arts in interdisciplinary and transdisciplinary networks of research in the sciences (or in networks of research in the sciences and the arts). Arts and artistic research help us to think and imagine beyond the 'written text'. Imagination and science fiction are references for the powers of fantasy and may inspire processes and scenarios of knowledge creation and knowledge production, long before a particular knowledge application or technology implementation is realistic ('thinking in possibilities before possible uses'). 'Fiction or science fiction may serve as stimulators for creative ideas, with the potential of being later transformed, at least partially (and of course not always), into new knowledge creation and production. We can also call this the creativity of knowledge creation' (Carayannis and Campbell 2010, p. 48). Arts and artistic research can be used for designing 'virtual worlds' that could not exist 'outside in the world' or that contradict the 'outside world', leading to paradoxical phenomena and furthermore to questions of what reality is or 'what really exists?'. One example is the Dutch graphic artist M.C. Escher (Maurits Cornelis Escher), who lived from 1898 until 1972 ${ }^{j}$. Escher engaged in drawing 'impossible constructions ${ }^{\mathrm{k}}$ that actually represent 'logical contradictions' (seen from a certain perspective of perception). Two famous drawings of his are 'Ascending and Descending' (1960) ${ }^{1}$ and 'Waterfall' (1961) ${ }^{\mathrm{m}}$. We could speculate whether the arts help us in seeing 'impossible worlds'. Is there a contradiction between the picture (image) and a conventional logical explanation, which reality is truer (or is already this wording a contradiction in itself)? These briefly discussed examples illustrate only tentatively and fragmentarily (in a partial manner) the whole spectrum of epistemic implications of arts and artistic research that appear to be possible. Further research and further artistic work is necessary. ${ }^{\mathrm{n}}$

Innovation systems in conceptual evolution: Mode 3 knowledge production in Quadruple and Quintuple Helix innovation systems

Universities, or higher education institutions (HEIs) in general, have three main functions: teaching and education, research (research and experimental development, R\&D), and the 'third mission' activities, for example, innovation (Campbell and Carayannis 2013, p. 5). In reference to 'arts universities', now the question and challenge arise as to what extent and in what way the arts universities differ from the (more traditional) universities in the sciences. Arts universities obviously place an emphasis on the arts, and the arts are not identical with the sciences. However, also arts universities frequently make references to the sciences, and thus, also arts universities can express competences in teaching and in carrying out research in the sciences. The other major challenge of arts universities is to engage in artistic research and 'arts-based innovation'. By this, arts universities (and 
other higher education institutions in the arts) are also being linked to and are being interlinked with national innovation systems and multi-level innovation systems. This widens the whole interdisciplinary and transdisciplinary spectrum of higher education systems. Artistic research furthermore complements the 'teaching of arts' at arts universities (see also the propositions formulated by Bast 2013). Hybrid and innovative combinations of universities of arts and universities of the sciences are possible and indicate organizational opportunities for promoting creativity.

University research, in a traditional understanding and in reference to universities in the sciences, focuses on basic research, often framed within a matrix of academic disciplines, and without a particular interest in the practical use of knowledge and innovation. This model of university-based knowledge production also is being called Mode 1 of knowledge production (Gibbons et al. 1994). Mode 1 is also compatible with the linear model of innovation, which is often being referred to Bush (1945). The linear model of innovation asserts that first there is basic research in the university context: gradually, this university research will diffuse out into society and the economy. It is then the economy and the firms that pick up the lines of university research and develop these further into knowledge application and innovation, for the purpose of creating economic and commercial success in the markets outside of the higher education system. Within the frame of linear innovation, there is a sequential 'first-then' relationship between basic research (knowledge production) and innovation (knowledge application).

The Mode-1-based understanding of knowledge production has been challenged by the new concept of Mode 2 of knowledge production, which was developed and proposed by Gibbons et al. (1994, pp. 3 to 8, 167). Mode 2 emphasizes a knowledge application and a knowledge-based problem solving that involves and encourages the following principles: 'knowledge produced in the context of application', 'transdisciplinarity', 'heterogeneity and organizational diversity', 'social accountability and reflexivity', and 'quality control' (see furthermore Nowotny et al. 2001, 2003, 2006). Key in this setting is the focus on a knowledge production in contexts of application. Mode 2 expresses and encourages clear references to innovation and innovation models. The linear model of innovation also has become challenged by non-linear models of innovation, which are interested in drawing more direct connections between knowledge production and knowledge application, where basic research and innovation are being coupled together not in a first-then, but in an 'as well as' and 'parallel' (parallelized) relationship (Campbell and Carayannis 2012). Mode 2 appears also to be compatible with non-linear innovation and its ramifications.

The Triple Helix model of knowledge, innovation, and university-industry-government relations, which was introduced and developed by Henry Etzkowitz and Loet Leydesdorff (2000, pp. 111 to112), asserts a basic core model for knowledge production and innovation, where three 'helices' intertwine, by this creating a national innovation system. The three helices are identified by the following systems or sectors: academia (universities), industry (business), and state (government). Etzkowitz and Leydesdorff refer to 'university-industry-government relations' and networks, putting a particular emphasis on 'tri-lateral networks and hybrid organizations', where those helices overlap in a hybrid fashion. Etzkowitz and Leydesdorff (2000, p. 118) also explain how, in their view, the Triple Helix model relates to Mode 2: the 'Triple Helix overlay provides a model at the level of social structure for the explanation of Mode 2 as an historically emerging 
structure for the production of scientific knowledge, and its relation to Mode 1'. More recently, Leydesdorff (2012) also introduced the notion of N-Tuple of Helices.

Mode 1 and Mode 2 may be characterized as 'knowledge paradigms' that underlie the knowledge production (to a certain extent also the knowledge application) of higher education institutions and university systems. Success or quality, in accordance with Mode 1, may be defined as: 'academic excellence, which is a comprehensive explanation of the world (and of society) on the basis of "basic principles" or "first principles", as is being judged by knowledge producer communities (academic communities structured according to a disciplinary framed peer review system)'. Consequently, success and quality, in accordance with Mode 2, can be defined as: 'problem-solving, which is a useful (efficient, effective) problem-solving for the world (and for society), as is being judged by knowledge producer and knowledge user communities' (Campbell and Carayannis 2013, p. 32). A Mode 3 university, higher education institution, or higher education system would represent a type of organization or system that seeks creative ways of combining and integrating different principles of knowledge production and knowledge application (for example, Mode 1 and Mode 2), by this encouraging diversity and heterogeneity and also creating creative and innovative organizational contexts for research and innovation. Mode 3 encourages the formation of 'creative knowledge environments' (Hemlin et al. 2004). 'Mode 3 universities' and Mode 3 higher education institutions and systems are prepared to perform 'basic research in the context of application' (Campbell and Carayannis 2013, p. 34). This has furthermore qualities of non-linear innovation. Governance of higher education and governance in higher education must also be sensitive, whether a higher education institution operates on the basis of Mode 1, Mode 2, or a combination of these in Mode 3. The concept of 'epistemic governance' emphasizes that the underlying knowledge paradigms of knowledge production and knowledge application are being addressed by quality assurance and quality enhancement strategies, policies, and measures (Campbell and Carayannis 2013b, 2013c).

Emphasizing again a more systemic perspective for the Mode 3 knowledge production, a focused conceptual definition may be as follows (Carayannis and Campbell 2012, p. 49): Mode 3 '... allows and emphasizes the co-existence and co-evolution of different knowledge and innovation paradigms. In fact, a key hypothesis is: The competitiveness and superiority of a knowledge system or the degree of advanced development of a knowledge system are highly determined by their adaptive capacity to combine and integrate different knowledge and innovation modes via co-evolution, co-specialization and co-opetition knowledge stock and flow dynamics' (see Carayannis and Campbell 2009; on 'Co-Opetition', see Brandenburger and Nalebuff 1997). Analogies are being drawn and a co-evolution is being suggested between diversity and heterogeneity in advanced knowledge society and knowledge economy, political pluralism in democracy (knowledge democracy), and the quality of a democracy. The 'Democracy of Knowledge' refers to this overlapping relationship. As is being asserted, 'The Democracy of Knowledge, as a concept and metaphor, highlights and underscores parallel processes between political pluralism in advanced democracy, and knowledge and innovation heterogeneity and diversity in advanced economy and society. Here, we may observe a hybrid overlapping between the knowledge economy, knowledge society and knowledge democracy' (Carayannis and Campbell 2012, p. 55). The Democracy of Knowledge, therefore, is further reaching than the earlier idea of the 'Republic of Science' (Polanyi 1962). 
The main focus of the Triple Helix innovation model concentrates on universityindustry-government relations (Etzkowitz and Leydesdorff 2000). In that respect, Triple Helix represents a basic model or a core model for knowledge production and innovation application. The models of the Quadruple Helix and Quintuple Helix innovation systems are designed to comprehend already and to refer to an extended complexity in knowledge production and knowledge application (innovation); thus, the analytical architecture of these models is broader conceptualized. To use metaphoric terms, the Quadruple Helix embeds and contextualizes the Triple Helix, while the Quintuple Helix embeds and contextualizes the Quadruple Helix (and Triple Helix). The Quadruple Helix adds as a fourth helix the media-based and culture-based public, the civil society, and arts, artistic research, and arts-based innovation (Carayannis and Campbell 2009, 2012, p. 14; see also Danilda et al. 2009). The Quadruple Helix also could be emphasized as the perspective that specifically brings in the dimension of democracy or the context of democracy for knowledge, knowledge production, and innovation. The Quintuple Helix innovation model even is more comprehensive in its analytical and explanatory stretch and approach, adding furthermore the fifth helix (and perspective) of the 'natural environments of society' (Carayannis and Campbell 2010, p. 62) (see Figures 4 and 2).

The Triple Helix is explicit in acknowledging the importance of higher education for innovation. However, it could be argued that the Triple Helix sees knowledge production and innovation in relation to economy; thus, the Triple Helix models first of all (primarily) the economy and economic activity. In that sense, the Triple Helix frames the knowledge economy. The Quadruple Helix brings in the additional perspective of society (knowledge society) and of democracy (knowledge democracy). The Quadruple Helix innovation system understanding emphasizes that sustainable development of and in economy (knowledge economy) requires that there is a co-evolution of knowledge economy and knowledge society and knowledge democracy. The Quadruple Helix even encourages the perspectives of knowledge society and of knowledge democracy for supporting, promoting, and advancing knowledge production (research) and knowledge application (innovation). Furthermore, the Quadruple Helix is also explicit that not only universities (higher education institutions) of the sciences, but also universities (higher education institutions) of the arts should be regarded as decisive and determining institutions for advancing next-stage innovation systems: the interdisciplinary and transdisciplinary connection of sciences and arts creates crucial and creative combinations for promoting and supporting innovation. Here, in fact, lies one of the keys for future success. The concept and term of 'social ecology' refers to 'society-nature interactions' between 'human society' and the 'material world' (see, for example, Fischer-Kowalski and Haberl 2007). The European Commission (2009) identified the necessary socio-ecological transition of economy and society not only as one of the great next-phase challenges, but also as an opportunity, for the further progress and advancement of knowledge economy and knowledge society. The Quintuple Helix refers to this socio-ecological transition of society, economy, and democracy, and the Quintuple Helix innovation system is therefore ecologically sensitive. Quintuple Helix bases its understanding of knowledge production (research) and knowledge application (innovation) on social ecology (see Figure 5). Environmental issues (such as global warming) represent issues of concern and of survival for humanity and human civilization. But the Quintuple Helix translates environmental and ecological issues of concern also in potential opportunities, by identifying them as possible 


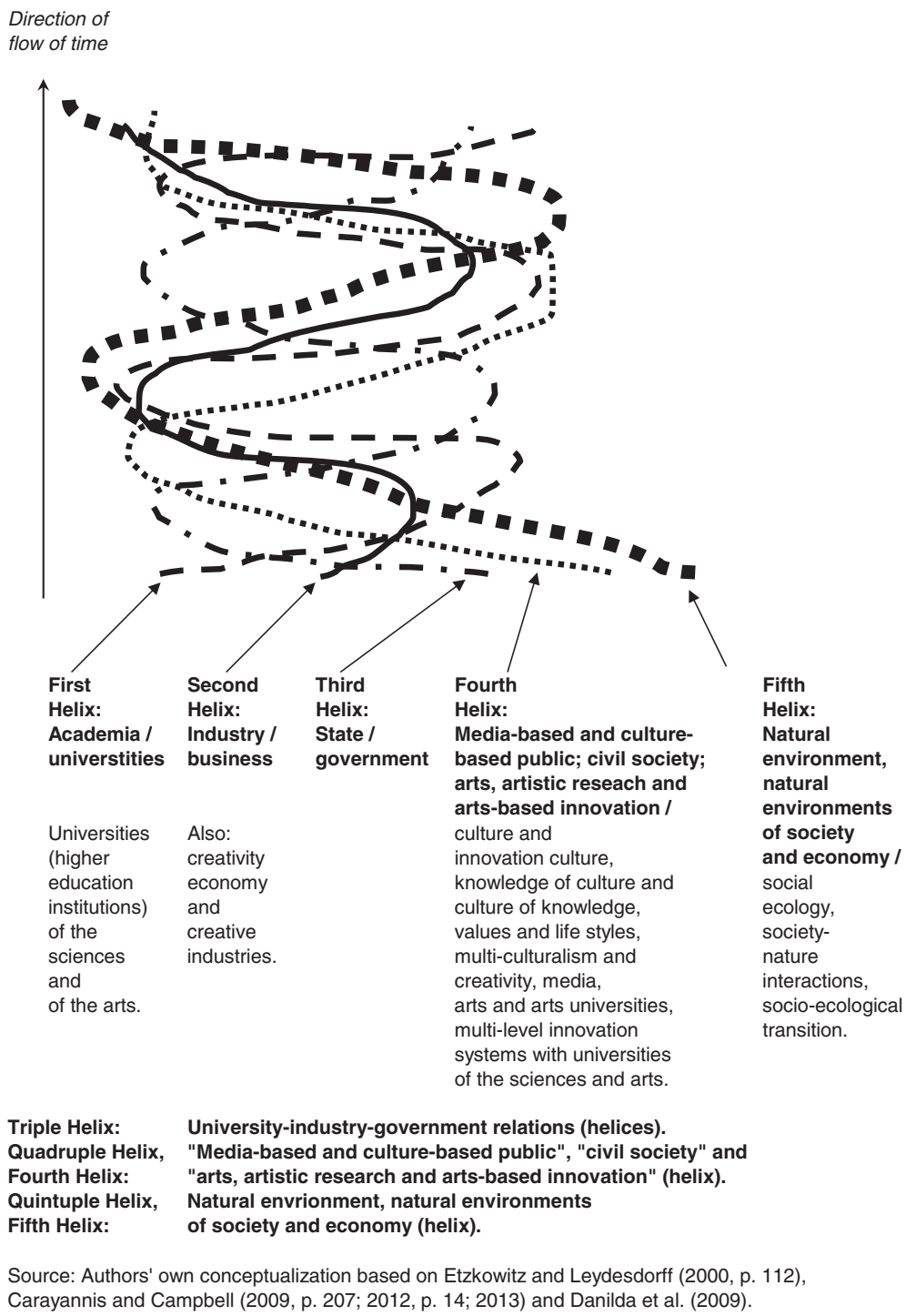

Source: Authors' own conceptualization based on Etzkowitz and Leydesdorff (2000, p. 112), Carayannis and Campbell (2009, p. 207; 2012, p. 14; 2013) and Danilda et al. (2009).

Figure 4 The Quadruple and Quintuple Helix innovation systems.

drivers for future knowledge production and innovation (Carayannis et al. 2012). This, finally, defines also opportunities for the knowledge economy. “The Quintuple Helix supports here the formation of a win-win situation between ecology, knowledge and innovation, creating synergies between economy, society and democracy" (Carayannis et al. 2012, p. 1).

\section{Conclusions}

The terms and concepts of Mode 3 knowledge production and Quadruple Helix innovation systems were first introduced to international academic debate by Carayannis and Campbell $(2006,2009)$ and were later developed further (Carayannis and Campbell 2012). The same applies to the Quintuple Helix (Carayannis and Campbell 2010). From the beginning, the media-based and culture-based public as well as universities and other higher education institutions of the arts were being regarded as crucial attributes and components of the Quadruple and Quintuple Helix innovation systems, implying that arts 


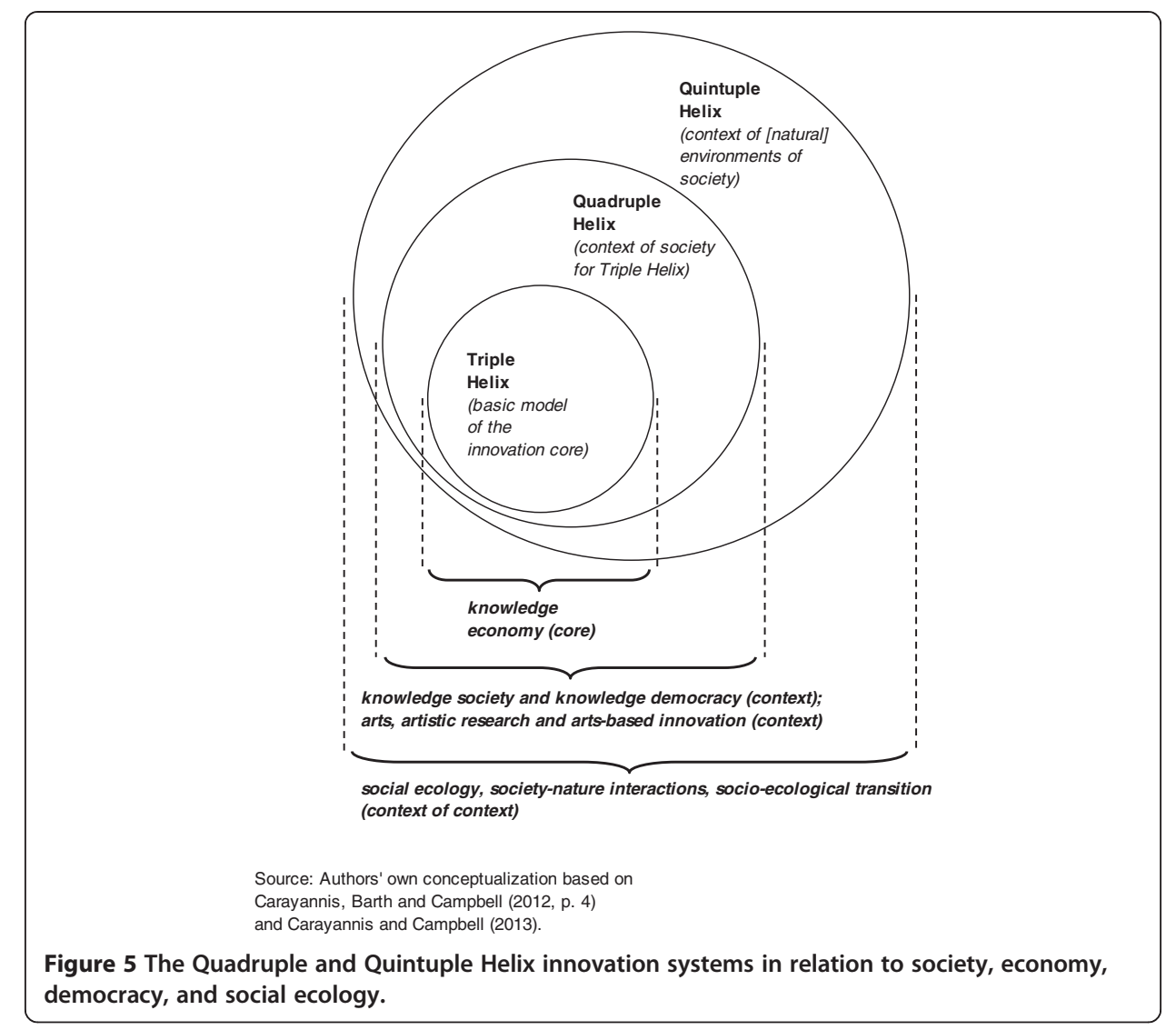

are essential for the progress and evolution of innovation systems (see again Figures 4 and 2). In our analysis here, we developed more specifically the Quadruple and Quintuple Helix innovation systems in terms and in favor of arts, artistic research, and arts-based innovation. We wanted to demonstrate the full momentum and flexibility of the Quadruple and Quintuple Helix for conceptually addressing and integrating art and arts.

More generally speaking, further ramifications of Mode 3 knowledge production in Quadruple Helix and Quintuple Helix innovation systems are as follows:

1. Multi-level innovation systems, the global and the local (GloCal): Lundvall was pivotal for introducing the concept of the 'national innovation system'. Lundvall (1992, pp. 1, 3) explicitly acknowledges that national innovation systems are challenged in permanence (but are also extended) by regional as well as global innovation systems. Here, Kuhlmann (2001, pp. 960 to 961) could be paraphrased, and the assertion that as long as nation states and nation state-based political systems exist, it is plausible to use the concept of the national innovation system. More comprehensive in its analytical architecture than the national innovation system is the concept of the 'multi-level innovation system' (Carayannis and Campbell 2012, pp. 32 to 35). In a spatial understanding, multi-level innovation systems compare the national not only with the sub-national (regional, local), but also with the transnational and global levels (see, for example, Kaiser and Prange 2004; furthermore, see Pfeffer 2012). However, it is also important to extend multi-level innovation systems to the challenges and potential benefits and opportunities of a non-spatial meaning, 
understanding, and 'mapping': 'Therefore, multi-level systems of knowledge as well as multi-level systems of innovation are based on spatial and non-spatial axes. A further advantage of this multi-level systems architecture is that it results in a more accurate and closer-to-reality description of processes of globalization and gloCalization' (Carayannis and Campbell 2012, p. 35).

2. Linear and non-linear innovation: Knowledge application and innovation are being challenged and driven out of an interest of combining and integrating linear and non-linear innovation. Keys to here are diversity, heterogeneity, and pluralism of different knowledge and innovation modes, and their linking together via an architecture of co-evolving networks. Firms, universities, and other organizations can engage (at the same) in varying and multiple technology life cycles at different levels of maturity. Another way, how to think non-linear innovation is being suggested by the concept of cross-employment (Campbell 2011; Campbell 2013a). As a form and type of multi-employment, cross-employment emphasizes that the same individual person may be employed by two (or more) organizations at the same time, where one organization could be located closer to knowledge production and the other to knowledge application (innovation): if those organizations are also rooted in different sectors, then cross-employment acts also as a trans-sectoral networking (Campbell and Caraynnis 2013, pp. 65, 68). Cross-employment can furthermore bridge different sectors and disciplines in the sciences with different disciplines in the arts. What results is a 'Mode 3 Innovation Ecosystem': 'This parallel as well as sequentially time-lagged unfolding of technology life cycles also expresses characteristics of Mode 2 and of nonlinear innovation, because organizations (firms and universities) often must develop strategies of simultaneously cross-linking different technology life cycles. Universities and firms (commercial and academic firms) must balance the nontriviality of a fluid pluralism of technology life cycles' (Carayannis and Campbell 2012, p. 37; see furthermore Dubina et al. 2012). The relationship between networks, 'cooperation and competition' (Co-Opetition), represents a challenge and sensitive issue and allows for different creative answers in organizational representation and manifestation.

3. Twenty-first century Fractal Research, Education and Innovation Ecosystem (FREIE): Here, the understanding of FREIE is 'This is a multilayered, multimodal, multinodal, and multilateral system, encompassing mutually complementary and reinforcing innovation networks and knowledge clusters consisting of human and intellectual capital, shaped by social capital and underpinned by financial capital' (Carayannis and Campbell 2012, p. 3).

4. Linear and non-linear innovation, and the causality of 'if-then' and of 'if-if' relations: The hybrid overlapping of linear innovation and of non-linear innovation displays also possible ramifications and draws associations to models of causality and their re-modeling. "We can speculate, whether this parallel integration of linearity and nonlinearity not also encourages a new approach of paralleling in our theorizing and viewing of causality: in epistemic (epistemological) terms, the so-called if-then relationships could be complemented by (a thinking in) 'if-if" relations' (Carayannis and Campbell 2012, p. 24; see also Campbell 2009, p. 123).

At the beginning of our analysis (in the introduction), we formulated the following research questions: How does artistic research relate to research in the sciences, and 
how does artistic research relate to innovation and innovation systems? We were inclined to develop the interrelation and interlinkage between arts, research, and innovation on the basis of the concepts of the Quadruple and Quintuple Helix innovation systems. We wanted to address art and artistic research (AAA) in the context of the Quadruple Helix and Quintuple Helix. 'Arts, research, innovation, and society' may be regarded as a program with implications for theory, policy, and practice. ${ }^{\circ}$ In the following, we develop further a few more propositions. These propositions should be regarded as input for discussion and discourse:

1. 'Arts as a manifestation of knowledge': By defining arts as a manifestation of knowledge (in complementary extension of a more traditional understanding of the aesthetic dimension of arts), the artistic research and arts-based innovation then interflow directly with art and arts. Artistic research helps to explain the arts. Artistic research also contributes to the epistemic potential of the arts and in arts. Universities and other higher education institutions of the arts are challenged to respond to artistic research and to implement strategies for developing artistic research, which also informs and drives university teaching. Through knowledge creation, knowledge production, knowledge application, and knowledge use, research in the arts and arts-based innovation are being interconnected with research in the sciences and sciences-based innovation. Arts and artistic research add to the interdisciplinary and transdisciplinary spectrum of research organizations and of research networks and can assist the sciences (also science) in building interdisciplinary arrangements. Interdisciplinarity often qualifies as a good basis for transdisciplinarity. Arts and artistic research foster heterogeneous processes of diversification and pluralization within knowledge production and innovation. Arts and artistic research promote creativity, which are keys for knowledge creation, knowledge production, and innovation.

2. Art and artistic research ${ }^{\mathrm{p}}$ in Quadruple and Quintuple Helix innovation systems: The concepts of the Quadruple Helix and Quintuple Helix innovation systems are explicitly sensitive for the roles of arts and of artistic research for innovation. Within the context of that line of thinking, arts, artistic research, and arts-based innovation (AAA) are essential for the further evolution and progress of innovation systems. Universities and other higher education institutions of the arts represent crucial organizations for innovation systems (national and multi-level innovation systems). In multi-level innovation systems, the global, national, and local innovation systems co-evolve in parallel and in being mutually intertwined.

3. 'Arts, research, innovation, and society' and the quality in economy and the quality of democracy: Innovation may not be narrowed down to economic concerns and economic activities. Innovation is more than only economics. Arts, research, innovation, and society contribute to creating the basis for new models of economic growth, where 'growth in quality' challenges the traditional focus on 'quantitative growth' of selected economic benchmarks or indicators. Arts, artistic research, and arts-based innovation are keys for advanced economies as well as the emerging markets. Arts, research, innovation, and society furthermore interrelate and cross-link with Quality of Democracy. This indicates opportunities for a creative design or processes of creatively designing the further co-evolution of knowledge economy, knowledge society, and knowledge democracy. 
4. Arts, artistic research, arts-based innovation, and 'Creative Knowledge Environments': Creative Knowledge Environments (Hemlin et al. 2004) are interested in contributing to capabilities of knowledge creation, knowledge production, and innovation in organizations and in networks. Cross-employment (Campbell 2013a) defines one strategy for doing so (also for non-linear innovation). Arts, artistic research, and arts-based innovation furthermore represent approaches that add to the formation of Creative Knowledge Environments. Arts, artistic research, and arts-based innovation and innovations are at least 'potentially' relevant to all organizations and networks that are engaged in research (knowledge creation and knowledge production) and innovation (knowledge application and knowledge use). This clearly demonstrates the possibilities and opportunities of arts, artistic research, and arts-based innovation for the sustainable development and the 'innovative re-invention' of organizations and networks that are involved in and perform in knowledge production. There is a need for more creative organizational design. In aggregation, this is also of relevance for whole innovation systems.

Arts, democracy, and innovation co-evolve. At the beginning of our article analyses, we introduced the blueprint for a vision and manifesto on knowledge production and innovation in Quadruple Helix innovation systems. The Quadruple Helix regards itself to be human-centered oriented. While for the Triple Helix model the existence of a democracy is not (per se) necessary for knowledge production and innovation, the Quadruple Helix is here more explicit. The way how the Quadruple Helix is being engineered, designed, and architected clearly shows that there cannot be a Quadruple Helix innovation system without democracy or a democratic context. The following attributes and components define the fourth helix in the Quadruple Helix: media-based and culture-based public, civil society, and arts, artistic research, and arts-based innovation. By this, the fourth helix in the Quadruple Helix represents the perspective of the dimension of democracy or the context of democracy for knowledge, knowledge production, and innovation. This is particularly true when democracy is being understood to transcend the narrow understanding of being primarily based on or being primarily rooted in government institutions (within Triple Helix). Civil society, culture-based public, quality of democracy, and sustainable development convincingly demonstrate what the rationales and requirements are for conceptualizing democracy broader (Campbell and Carayannis 2013a). ${ }^{\mathrm{q}}$ Political pluralism in a democracy co-evolves with the pluralism, diversity, and heterogeneity of knowledge, knowledge production, and innovation (Democracy of Knowledge, see Carayannis and Campbell, 2009, 2012, p. 55). We postulate here a congruence of structures and processes in democracy and in innovation systems. The Quintuple Helix extends the Quadruple Helix by aspects of the natural environments of society and economy, the social ecology, and the socio-ecological transition. Also, this environmental context of society can be better addressed in a democracy than in a non-democracy. The current world appears to be challenged by a race between developing democracies versus emerging autocracies over knowledge production and innovation.

The contributions of arts, arts-based research, and arts-based innovation to knowledge production and innovation systems are manifold. Art also helps us to think beyond the box. Finally, we want to engage in an artistic 'turn of turns'. In an attempt of free 
association with the work of M.C. Escher ${ }^{\mathrm{r}}$, we close here the analysis with the following two words: Ascending Waterfalls. This is the beginning of beginning.

\section{Methods}

The article focuses on creatively designing, redesigning, and discussing concepts of knowledge production and innovation. The points of departure are the Triple Helix, Quadruple Helix, and Quintuple Helix for innovation, and Mode 1, Mode 2, and Mode 3 for knowledge production. These concepts are all published and thus publicly accessible. Particularly, the concept of the Quadruple Helix innovation system is being discussed and conceptually further developed in a twofold assessment approach: (1) democracy and knowledge production and innovation, and (2) art, arts-based research, and arts-based innovation. This should contribute to a continuous discourse building of the Quadruple Helix. The emphasis is on a deepening reflection.

\section{Endnotes}

${ }^{a}$ Concepts and terms in reference to knowledge production and innovation will be explained in greater detail later in this article.

${ }^{b}$ For example, see on Google Scholar the tracking of references to the concept of the Quadruple Helix innovations systems: http://scholar.google.at/scholar? cites $=2775322365902273481 \&$ as_sdt $=2005 \&$ sciodt $=0,5 \& \mathrm{hl}=\mathrm{en}$.

'Within the context of our analysis, the plural term 'sciences' always includes the natural sciences, life sciences, and also the social sciences and humanities (human sciences). For us, the sciences address the whole and complete disciplinary spectrum. Therefore, 'sciences' is not equivalent to science. When we use the shorter expression 'scientific research', we actually always mean the research in all of the sciences.

${ }^{\mathrm{d}}$ Of course, depending on how the sciences or knowledge production in the sciences is defined or is being defined, we may arrive here at different conclusions. Perhaps, the sciences (or pre-forms of the sciences) are just as old as the arts (pre-forms of arts). Reasoning and aesthetic sensitivity represent universal categories of humanity.

eIn her Master thesis, Derya Öcal also reflects on the question, What is Art? Was ist Kunst?

${ }^{\mathrm{f}} \mathrm{We}$ would like to add that art also reflects culture and the experiences on which culture is being based or which influence culture. This is also being expressed and recognized in the following: The Knowledge of Culture and the Culture of Knowledge (Carayannis and Pirzadeh 2014).

'Perhaps it would be fairer to talk here about the 'beauties' or 'non-beauties' always in the plural form (in contrast to a 'singular' beauty or non-beauty). Depending on the specific context (time, era or society), the understanding of the beautiful often varied or varies. Also, within a specific context, quite different understandings of the beautiful can co-exist (partly in contradiction to each other). In that sense, beauty obviously depends upon culture.

${ }^{\mathrm{h}}$ In the context of our analysis here, we use knowledge production and knowledge creation as interchangeable concepts. We could speculate whether 'knowledge creation' fits better for purposes of describing processes (knowledge-based processes) in the arts and in artistic research than the term 'knowledge production'. 
${ }^{\mathrm{i}}$ Epistemology or an 'epistemic base' may apply as a concept to very different fields. For example, also policy and policies can be discussed under aspects of 'epistemic governance' (Campbell and Carayannis 2013b, c). In fact, to utilize an epistemic base in unusual contexts has all the qualities of a potentially innovative approach or approaching.

'See http://en.wikipedia.org/wiki/M._C._Escher.

${ }^{\mathrm{k}}$ For an overview, see http://www.mcescher.com/gallery/.

${ }^{\mathrm{l}} \mathrm{See}$ http://www.mcescher.com/gallery/impossible-constructions/ascending-and-descending/ and http://en.wikipedia.org/wiki/Ascending_and_Descending.

${ }^{\mathrm{m}} \mathrm{See} \mathrm{http://www.mcescher.com/gallery/impossible-constructions/waterfall/} \mathrm{and} \mathrm{http://en.}$ wikipedia.org/wiki/Waterfall_(M._C._Escher).

${ }^{n}$ I I would add that arts and expressions of arts evolve with time and styles. And the beauty of it is that, unlike reality, arts make everything possible ("impossible world") by the simple fact that art is a matter of perception with limitless possibilities. There is more freedom in arts than in real life, and even more than for science fiction were some plausible technicality should be featured' (direct quote from an anonymous review and reviewer for this article).

${ }^{\circ}$ See also the announcement of the close launch of a whole new book series on the topic of 'arts, research, innovation, and society'. The title of this book series is exactly: Arts, Research, Innovation and Society (http://www.springer.com/series/11902).

${ }^{\mathrm{P}}$ In the context of our analysis here, art and artistic research (also arts, artistic research, and arts-based innovation) refers to a conceptual 'Triple A' of the qualities of arts-based knowledge production and arts-based innovation.

${ }^{\mathrm{q}}$ To turn this line of thinking, autocracies are not interested to allow the development of a free and mature civil society. On the contrary, autocracies want to control and suppress the rise of an independent civil society.

${ }^{\mathrm{r}}$ See again our analysis in the 'Arts and Artistic Research' section.

Competing interests

The authors declare that they have no competing interests.

Authors' contributions

EGC and DFJC jointly developed (co-created) the concepts of the Quadruple Helix and Quintuple Helix innovation systems. The competence background of EGC is in economics and of DFJC in political science. Both authors are fascinated by arts, arts-based research, and arts-based innovation. Both authors read and approved the final manuscript.

\section{Author details}

${ }^{1}$ European Union Research Center, Department of Information Systems \& Technology Management, School of Business, The George Washington University, Duquès Hall, Funger Hall, Suite 515C, 2201 G Street, NW, Washington, D.C 20052, USA. ${ }^{2}$ Unit for Quality Enhancement (UQE), University of Applied Arts Vienna, Oskar Kokoschka-Platz 2, Vienna 1010, Austria. ${ }^{3}$ Faculty for Interdisciplinary Studies (iff), Institute of Science Communication and Higher Education Research (WIHO), Alpen-Adria-University Klagenfurt, Schottenfeldgasse 29, Vienna 1070, Austria.

Received: 24 April 2014 Accepted: 19 June 2014

Published online: 20 August 2014

References

Arnold, M. (2013a). Interdisciplinary research (interdisciplinarity). In EG Carayannis, N Dubina, N Seel, DFJ Campbell, \& D Uzunidis (Eds.), Encyclopedia of creativity, invention, innovation and entrepreneurship (pp. 1105-1113). New York, NY: Springer. http://link.springer.com/referenceworkentry/10.1007/978-1-4614-3858-8_302 and http://www. springerreference.com/docs/html/chapterdbid/378730.html.

Arnold, M. (2013b). Transdisciplinary research (transdisciplinarity). In EG Carayannis, IN Dubina, N Seel, DFJ Campbell, \& D Uzunidis (Eds.), Encyclopedia of creativity, invention, innovation and entrepreneurship (pp. 1819-1828). New York, NY: Springer. http://link.springer.com/referenceworkentry/10.1007/978-1-4614-3858-8_337 and http://www. springerreference.com/docs/html/chapterdbid/378740.html.

Bast, G. (2013). Preparing a "creative revolution" - arts and universities of the arts in the creative knowledge economy. In EG Carayannis, IN Dubina, N Seel, DFJ Campbell, \& D Uzunidis (Eds.), Encyclopedia of creativity, invention, innovation and 
entrepreneurship (pp. 1471-1476). New York, NY: Springer. http://link.springer.com/referenceworkentry/10.1007/978-14614-3858-8_442 and http:/www.springerreference.com/docs/html/chapterdbid/378818.html.

Brandenburger, AM, \& Nalebuff, BJ. (1997). Co-Opetition. New York, NY: Doubleday.

Bush, V. (1945). Science: the endless frontier. Washington, D.C: United States Government Printing Office. http://www.nsf. gov/od/lpa/nsf50/vbush1945.htm\#transmittal.

Campbell, DFJ. (2009). "Externe Umwelten". Außensichten auf das iff. In M Arnold (Ed.), iff. Interdisziplinäre Wissenschaft im Wandel (pp. 99-134). Vienna: LIT.

Campbell, DFJ. (2011). Wissenschaftliche "Parallelkarrieren" als Chance. Wenn Wissenschaft immer öfter zur Halbtagsbeschäftigung wird, könnte eine Lösung im "Cross-Employment” liegen. Guest Commentary for DIE PRESSE (February 2, 2011). http://diepresse.com/home/bildung/meinung/635781/Wissenschaftliche-Parallelkarrieren-alsChance?direct=635777\&_vl_backlink=/home/bildung/index.do\&selChannel=500.

Campbell, DFJ. (2013a). Cross-employment. In EG Carayannis, IN Dubina, N Seel, DFJ Campbell, \& D Uzunidis (Eds.), Encyclopedia of creativity, invention, innovation and entrepreneurship (pp. 503-508). New York, NY: Springer. http:// link.springer.com/referenceworkentry/10.1007/978-1-4614-3858-8_254 and http://www.springerreference.com/docs/ html/chapterdbid/378719.html.

Campbell, GS. (2013b). Speaking pictures: innovation in fine arts. In EG Carayannis, IN Dubina, N Seel, DFJ Campbell, \& D Uzunidis (Eds.), Encyclopedia of creativity, invention, innovation and entrepreneurship (pp. 1716-1722). New York, NY: Springer. http://link.springer.com/referenceworkentry/10.1007/978-1-4614-3858-8_484 and http://www. springerreference.com/docs/html/chapterdbid/378853.html.

Campbell, DFJ, \& Carayannis, EG. (2012). Lineare und nicht-lineare knowledge production: innovative Herausforderungen für das Hochschulsystem. Zeitschrift für Hochschulentwicklung, 7(2), 64-72. http://www.zfhe.at/index.php/zfhe/ article/view/448.

Campbell, DFJ, \& Carayannis, EG. (2013a). Quality of democracy and innovation. In EG Carayannis, IN Dubina, N Seel, DFJ Campbell, \& D Uzunidis (Eds.), Encyclopedia of creativity, invention, innovation and entrepreneurship (pp. 15271534). New York, NY: Springer. http://link.springer.com/referenceworkentry/10.1007\%2F978-1-4614-3858-8_509\# and http://www.springerreference.com/docs/html/chapterdbid/378878.html.

Campbell, DFJ, \& Carayannis, EG. (2013b). Epistemic governance in higher education. Quality enhancement of universities for development. SpringerBriefs in Business. New York, NY: Springer. http://www.springer.com/business+\%26 +management/organization/book/978-1-4614-4417-6.

Campbell, DFJ, \& Carayannis, EG. (2013c). Epistemic governance and epistemic innovation policy. In EG Carayannis, IN Dubina, N Seel, DFJ Campbell, \& D Uzunidis (Eds.), Encyclopedia of creativity, invention, innovation and entrepreneurship (pp. 697-702). New York, NY: Springer. http://link.springer.com/referenceworkentry/10.1007/978-14614-3858-8_271 and http://www.springerreference.com/docs/html/chapterdbid/378723.html.

Campbell, DFJ, \& Carayannis, EG. (2015). Explaining and comparing quality of democracy in Quadruple Helix structures: the quality of democracy in the United States and in Austria, challenges and opportunities for development. In EG Carayannis, DFJ Campbell, \& MP Efthymiopoulos (Eds.), Cyber-development, cyber-democracy and cyber-defense. Challenges, opportunities and implications for theory, policy and practice. New York, NY: Springer. http://www.springer. com/social+sciences/political+science/book/978-1-4939-1027-4 (forthcoming).

Carayannis, EG, Barth, TD, \& Campbell, DFJ. (2012). The Quintuple Helix innovation model: global warming as a challenge and driver for innovation. Journal of Innovation and Entrepreneurship, 1(1), 1-12. http://www.innovationentrepreneurship.com/content/pdf/2192-5372-1-2.pdf.

Carayannis, EG, \& Campbell, DFJ. (2006). "Mode 3": meaning and implications from a knowledge systems perspective. In EG Carayannis \& DFJ Campbell (Eds.), Knowledge creation, diffusion, and use in innovation networks and knowledge clusters. A comparative systems approach across the United States, Europe and Asia (pp. 1-25). Westport, Connecticut: Praeger.

Carayannis, EG, \& Campbell, DFJ. (2009). "Mode 3" and "Quadruple Helix": toward a 21st century fractal innovation ecosystem. International Journal of Technology Management, 46(3/4), 201-234. http://www.inderscience.com/ browse/index.php?journallD=27\&year=2009\&vol=46\&issue=3/4 and http: $/ / w w w$.inderscience.com $/$ search/index . php?action=record\&rec_id $=23374 \&$ prevQuery $=\& p s=10 \& m=0 r$.

Carayannis, EG, \& Campbell, DFJ. (2010). Triple Helix, Quadruple Helix and Quintuple Helix and how do knowledge, innovation and the environment relate to each other? A proposed framework for a trans-disciplinary analysis of sustainable development and social ecology. International Journal of Social Ecology and Sustainable Development, 1 (1), 41-69. http://www.igi-global.com/free-content/41959 and http://www.igi-global.com/article/triple-helix-quadruple-helix-quintuple/41959.

Carayannis, EG, \& Campbell, DFJ. (2012). Mode 3 knowledge production in Quadruple Helix innovation systems. 21stcentury democracy, innovation, and entrepreneurship for development. SpringerBriefs in Business. New York, NY: Springer. http://www.springer.com/business+\%26+management/book/978-1-4614-2061-3.

Carayannis, EG, \& Campbell, DFJ. (2013). Mode 3 knowledge production in quadruple helix innovation systems: Quintuple Helix and social ecology. In EG Carayannis, IN Dubina, N Seel, DFJ Campbell, \& D Uzunidis (Eds.), Encyclopedia of creativity, invention, innovation and entrepreneurship (pp. 1293-1300). New York, NY: Springer. http://link.springer.com/referenceworkentry/10.1007/978-1-4614-3858-8_310 and http://www.springerreference. com/docs/html/chapterdbid/378732.html.

Carayannis, EG, \& Kaloudis, A. (2010). A Time for action and a time to lead: democratic capitalism and a new "new deal" for the US and the world in the twenty-first century. Journal of the Knowledge Economy, 1(1), 4-17. http://link. springer.com/article/10.1007/s13132-009-0002-y.

Carayannis, EG, \& Pirzadeh, A. (2014). The knowledge of culture and the culture of knowledge. Implications for theory, policy and practice. Houndmills: Palgrave Macmillan. http://www.amazon.de/The-Knowledge-Culture-Implications-Practice/dp/ 1403942439/ref=sr_1_1?ie=UTF8\&qid=1403080044\&sr=8-1\&keywords=carayannis+knowledge+of + culture.

Damianisch, A. (2013). Artistic research. In EG Carayannis, IN Dubina, N Seel, DFJ Campbell, \& D Uzunidis (Eds.), Encyclopedia of creativity, invention, innovation and entrepreneurship (pp. 122-127). New York, NY: Springer. http://link.springer.com/referenceworkentry/10.1007/978-1-4614-3858-8_473 and http://www.springerreference. com/docs/html/chapterdbid/378843.html. 
Danilda, I, Lindberg, M, \& Torstensson, B-M. (2009). Women resource centres. A quattro helix innovation system on the European agenda. Paper. http://www.hss09.se/own_documents/Papers/3-11\%20-\%20Danilda\%20Lindberg\%20\&\% 20Torstensson\%20-\%20paper.pdf.

Dubina, IN, Carayannis, EG, \& Campbell, DFJ. (2012). Creativity economy and a crisis of the economy? Coevolution of knowledge, innovation, and creativity, and of the knowledge economy and knowledge society. Journal of the Knowledge Economy, 3(1), 1-24. http://link.springer.com/article/10.1007/s13132-011-0042-y.

Etzkowitz, H, \& Leydesdorff, L. (2000). The dynamics of innovation: from national systems and "Mode 2" to a triple helix of university-industry-government relations. Research Policy, 29, 109-123.

European Commission. (2009). The world in 2025. Rising Asia and socio-ecological transition. Brussels: European Commission (http://ec.europa.eu/research/social-sciences/pdf/the-world-in-2025-report_en.pdf).

Fischer-Kowalski, M, \& Haberl, H (Eds.). (2007). Socioecological transitions and global change. Trajectories of social metabolism and land use. Cheltenham: Edward Elgar.

Gibbons, M, Limoges, C, Nowotny, H, Schwartzman, S, Scott, P, \& Trow, M. (1994). The new production of knowledge. The dynamics of science and research in contemporary societies. London: Sage.

Hemlin, S, Allwood, CM, \& Martin, BR. (2004). Creative knowledge environments. The influences on creativity in research and innovation. Cheltenham: Edward Elgar.

Kaiser, R, \& Prange, H. (2004). The reconfiguration of national innovation systems - the example of German biotechnology. Research Policy, 33, 395-408.

Kuhlmann, S. (2001). Future governance of innovation policy in Europe - three scenarios. Research Policy, 30, 953-976.

Leydesdorff, L. (2012). The Triple Helix, Quadruple Helix, ..., and an N-Tuple of Helices: explanatory models for analyzing the knowledge-based economy? Journal of the Knowledge Economy, 3(1), 25-35. http://ink.springer.com/article/ 10.1007/s13132-011-0049-4.

Lundvall, B-Å (Ed.). (1992). National systems of innovation. Towards a theory of innovation and interactive learning. London: Pinter Publishers.

Mateus-Berr, R. (2013). Applied design thinking lab and creative empowering of interdisciplinary teams. In EG Carayannis, IN Dubina, N Seel, DFJ Campbell, \& D Uzunidis (Eds.), Encyclopedia of creativity, invention, innovation and entrepreneurship (pp. 73-116). New York, NY: Springer. http://link.springer.com/referenceworkentry/10.1007/978-14614-3858-8_437 and http://www.springerreference.com/docs/html/chapterdbid/378815.html.

Nowotny, H, Scott, P, \& Gibbons, M. (2001). Re-thinking science. Knowledge and the public in an age of uncertainty. Cambridge: Polity Press.

Nowotny, H, Scott, P, \& Gibbons, M. (2003). Mode 2 revisited: the new production of knowledge. Minerva, 41, 179-194.

Nowotny, H, Scott, P, \& Gibbons, M. (2006). Re-thinking science: Mode 2 in societal context. In EG Carayanni \& DFJ Campbell (Eds.), Knowledge creation, diffusion, and use in innovation networks and knowledge clusters. A comparative systems approach across the United States, Europe and Asia (pp. 39-51). Westport, Connecticut: Praeger.

Öcal, D. (2013). Kunst und Politik. [Art and Politics.] Master Thesis. Vienna: University of Vienna.

Park, HW. (2014). Transition from the Triple Helix to N-Tuple Helices? An interview with Elias G. Carayannis and David F. J. Campbell. Scientometrics, 99(1), 203-207. http://link.springer.com/article/10.1007\%2Fs11192-013-1124-3 and http://download.springer.com/static/pdf/907/art\%253A10.1007\%252Fs11192-013-1124-3.pdf? auth66=1397308723_4cb0003877af5305d5dc202280b9cd6d\&ext=.pdf.

Pfeffer, T. (2012). Virtualization of universities. Digital media and the organization of higher education institutions. New York, NY: Springer. http://www.springer.com/business+\%26+management/media+management/book/978-1-4614-2064-4.

Polanyi, M. (1962). The republic of science: its political and economic theory. Minerva, 1, 54-74. http://sciencepolicy. colorado.edu/students/envs_5100/polanyi_1967.pdf and http://fiesta.bren.ucsb.edu/ gsd/595e/docs/41.\% 20Polanyi_Republic_of_Science.pdf.

doi:10.1186/s13731-014-0012-2

Cite this article as: Carayannis and Campbell: Developed democracies versus emerging autocracies: arts, democracy, and innovation in Quadruple Helix innovation systems. Journal of Innovation and Entrepreneurship 2014 3:12.

\section{Submit your manuscript to a SpringerOpen ${ }^{\circ}$ journal and benefit from:}

- Convenient online submission

- Rigorous peer review

- Immediate publication on acceptance

- Open access: articles freely available online

- High visibility within the field

- Retaining the copyright to your article

Submit your next manuscript at $\boldsymbol{\nabla}$ springeropen.com 